\title{
Review Article \\ Theoretical Studies of Electronic Structure and Photophysical Properties of a Series of Indoline Dyes with Triphenylamine Ligand
}

\author{
Xue-Feng Ren, ${ }^{1}$ Jun Zhang, ${ }^{1}$ and Guo-Jun Kang ${ }^{1,2}$ \\ ${ }^{1}$ School of Chemical Engineering \& Technology, China University of Mining and Technology, Xuzhou 221008, China \\ ${ }^{2}$ Low Carbon Energy Institute, China University of Mining and Technology, Xuzhou 221008, China \\ Correspondence should be addressed to Guo-Jun Kang; gjkang@cumt.edu.cn
}

Received 9 March 2015; Accepted 15 April 2015

Academic Editor: Ruomeng Yu

Copyright (c) 2015 Xue-Feng Ren et al. This is an open access article distributed under the Creative Commons Attribution License, which permits unrestricted use, distribution, and reproduction in any medium, provided the original work is properly cited.

To design efficient organic sensitizer, a series of $\mathrm{D}-\pi$-A indoline dyes with different donor parts have been investigated by density functional theory (DFT) and time-dependent DFT (TD-DFT) approach. The molecular geometries, frontier molecular orbitals, and absorption spectra of these dyes have been systematically investigated to provide comprehensive understanding of the structureproperty relationships. Compared with D149, our designed dyes have proper HOMO and LUMO energy level, narrowed HOMOLUMO energy gap, and broadened absorption band by introducing the $\mathrm{N}\left(\mathrm{CH}_{3}\right)_{2}$ and $\mathrm{N}(\text { phenyl })_{2}$ groups at the donor part. Furthermore, the dimeric dyes and dye- $\left(\mathrm{TiO}_{2}\right)_{6}$ systems have been optimized by DFT method to simulate the intermolecular interactions, as well as interaction between the dyes dimmers and semiconductor interface, respectively. Through the analyses of absorption energies $\left(E_{\text {ads }}\right)$, energy levels of the HOMO and LUMO, light harvesting efficiency (LHE), and the driving force of electrons injections $\left(\Delta G_{\text {inject }}\right)$, it is found that the designed dyes should have improved optical properties by importing the $\mathrm{N}\left(\mathrm{CH}_{3}\right)_{2}$ group. This work is hoped to provide a theoretical guiding role in design of new dyes for dye-sensitized solar cells.

\section{Introduction}

Due to increasing energy demands and concerning global warming, scientists have paid tremendous effort on developing cheap and easily accessible renewable energy sources. Dye-sensitized solar cells (DSSCs) have been regarded as one of the most promising next-generation photovoltaic cells due to their potentially low fabrication costs, easy production, and flexibility compared to traditional silicon-based solar cells [1]. A typical DSSC is constructed with the dye sensitizer, dye-absorbed nanocrystalline semiconductor oxide (such as $\mathrm{TiO}_{2}$ or $\mathrm{ZnO}$ ), electrolyte containing $\mathrm{I}^{-} / \mathrm{I}_{3}{ }^{-}$ redox couples, and closed circuit. Obviously, the sensitizer plays a significant role for improving the efficiency of DSSCs. Therefore, considerable synthetic works have been carried out on Ru-based sensitizers [2-4] and metal-free organic dye sensitizers [5-10]. Among them, indoline dye sensitizers [11] have attracted much attention because of their high molar extinction coefficient, relatively less expensive, and low pollution of environmental. Although the significant progress has been made in the organic dyes, the conversion efficiency of indoline type dyes is still lower than the Ru-based sensitizer [12]. Therefore, the investigation on the organic dye is very important for realizing large-scale commercial production.

Except the massive synthesized research, theoretical studies have been accepted as extremely powerful and comparably low-cost tools for revealing the effect of chemical modifications on the optical properties [13-18]. In spite of outstanding electronic and optical properties of triphenylamine derivatives in solar cell [19-22], to our knowledge, there is no detailed study on indoline-containing materials coupled with triphenylamine as donor part. Consequently, in order to reveal the role of triphenylamine on the photophysical properties and develop more efficient dyes, the donor part of D149 dye is replaced by triphenylamine unit. Then, triphenylamine-containing indoline dyes are designed by introducing 

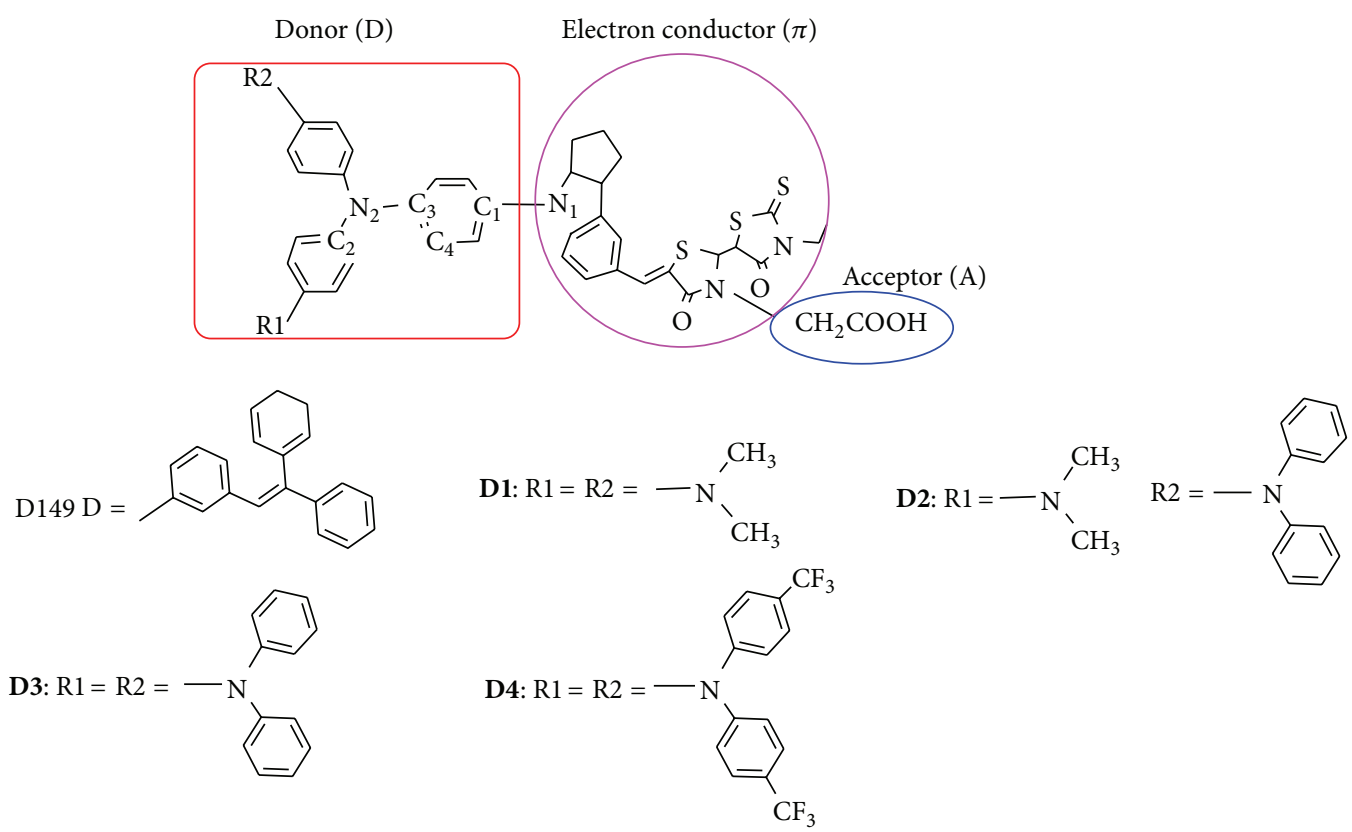

FIGURE 1: Sketch map of the studied dyes.

the $\mathrm{N}\left(\mathrm{CH}_{3}\right)_{2}, \mathrm{~N}(\text { phenyl })_{2}$, and $\mathrm{CF}_{3}$ at the donor part of D149 in this work (see Figure 1). A systematic comparison and analysis of the geometries, frontier molecular orbitals, and absorption spectra of these dyes are carried out. Furthermore, the light harvesting efficiency (LHE) and the driving force of electrons injections $\left(\Delta G_{\text {inject }}\right)$ are calculated to estimate the short-circuit photocurrent density. In addition, the electron coupling of dimeric dyes and dye- $\left(\mathrm{TiO}_{2}\right)_{6}$ systems is simulated by DFT method to testify the electron injection efficiency. This work is expected to reveal the effect of chemical modification on the DSSCs efficiency and provide valuable guidance for developing efficiency dyes.

\section{Computational Details}

All calculations were performed with the Gaussian 09 program package [23]. The density functional theory DFT (B3LYP) approach had been successfully used to calculate the ground geometries in indoline dye sensitizers [13-15, 24]. Therefore, in this work, the geometries structures of monomer and dimer dyes were fully optimized at the DFT level of B3LYP method $[25,26]$ using the 6-31G(d) basis set. Following the optimized geometry, the vibrational frequencies were calculated and the results confirmed that all the optimized monomer geometries were stable geometric structures. The absorption spectra of these dyes were investigated by TDDFT with the B3LYP approach associated with the polarized continuum model (PCM) $[27,28]$ in methanol media.

To investigate the electronic coupling interaction between these dyes and $\mathrm{TiO}_{2}$ nanoparticles, the absorption geometries of dyes $/\left(\mathrm{TiO}_{2}\right)_{6}$ clusters were calculated by B3LYP method. The 6-31G(d) basis sets were used for $\mathrm{C}, \mathrm{H}, \mathrm{O}, \mathrm{N}, \mathrm{S}$, and $\mathrm{F}$ atoms and LANL2DZ for $\mathrm{Ti}$ atom. Although $\left(\mathrm{TiO}_{2}\right)_{6}$ cluster is a simplistic model, it was believed to qualitatively reproduce the trend of the charge distribution [29]. The absorption energies $\left(E_{\mathrm{ads}}\right)$ of dyes $/\left(\mathrm{TiO}_{2}\right)_{6}$ were calculated by the following equation:

$$
E_{\text {ads }}=E_{\text {dye }}+E_{\left(\mathrm{TiO}_{2}\right)_{6}}-E_{\left[\text {dye } /\left(\mathrm{TiO}_{2}\right)_{6}\right]} \cdot
$$

The $E_{\text {dye }}, E_{\left(\mathrm{TiO}_{2}\right)_{6}}$, and $E_{\left.\left[\text {dye/( } \mathrm{TiO}_{2}\right)_{6}\right]}$ were the total energies of dyes, $\left(\mathrm{TiO}_{2}\right)_{6}$ cluster, and dye $/\left(\mathrm{TiO}_{2}\right)_{6}$, respectively.

The short-circuit current density $\left(J_{\text {sc }}\right)$ which is closely connected to the energy conversion efficiency $(\eta)$ of the solar cell [30] can be determined by the following equation [31]:

$$
J_{\text {sc }}=\int \operatorname{LHE}(\lambda) \Phi_{\text {inject. }} \eta_{\text {collect. }} d \lambda,
$$

where $\operatorname{LHE}(\lambda)$ is the light-harvesting efficiency at a given wavelength [31], $\Phi_{\text {inject }}$ is the electron injection efficiency to the semiconductor substrate, and $\eta_{\text {collect }}$ is the electron collection efficiency. $\eta_{\text {collect }}$ can be assumed as a constant in the same DSSCs with sole different dyes [32]. As a result, the enhancement of $J_{\text {sc }}$ should focus on improving the $\operatorname{LHE}(\lambda)$ and $\Phi_{\text {inject }}$. The $\Phi_{\text {inject }}$ is related to the driving force $\Delta G_{\text {inject }}$ for the electron injection. According to Preat's method [33], the $\Delta G_{\text {inject }}$ of electron injections from the excited states of dyes to semiconductor surface are calculated.

The light-harvesting efficiency $\operatorname{LHE}(\lambda)$ can be calculated with

$$
\operatorname{LHE}(\lambda)=1-10^{-f},
$$

where $f$ is the oscillator strength of the maximum absorption spectra of dyes.

\section{The Molecular Geometries of Dyes}

The sketch map and the optimized geometries of D149 and D1-D4 are shown in Figures 1 and 2, respectively. 


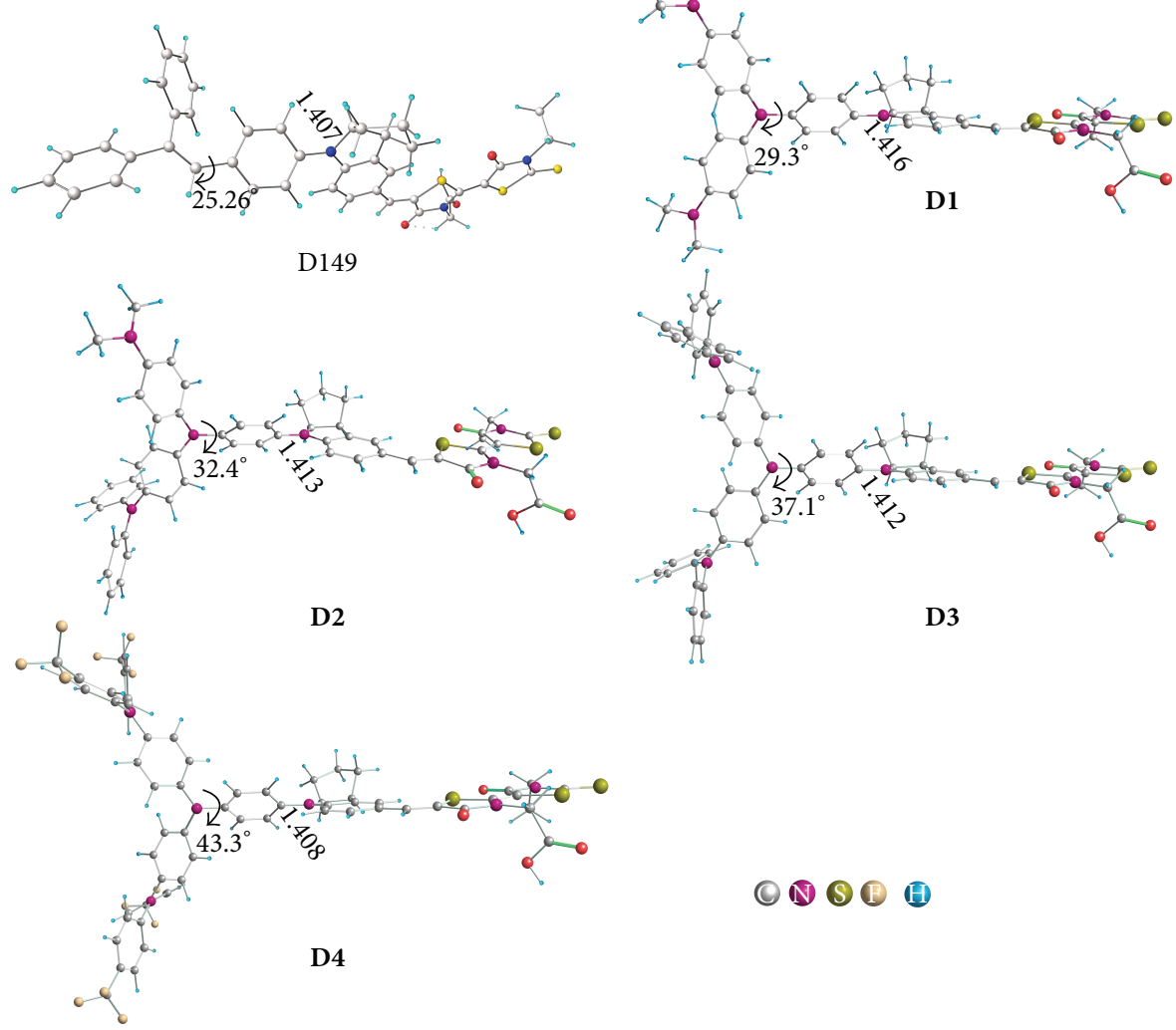

FIGURE 2: The optimized geometry of the studied dyes, together with the important bond length $(\AA)$ and dihedral angle $\left(^{\circ}\right)$.

The triphenylamine moiety, indoline and rhodanine group, and $\mathrm{CH}_{2} \mathrm{COOH}$ act as an electron donor (D), electron conductor $(\pi)$, and acceptor $(\mathrm{A})$, respectively. As shown in Figure 2, the dihedral angle of $\mathrm{C}_{4}-\mathrm{C}_{3}-\mathrm{N}_{2}-\mathrm{C}_{2}$ for $\mathrm{D} 149$ is $25.26^{\circ}$. D2 and D3 have steric obstruction conformation by gradually adding the $\mathrm{N}$ (phenyl) ${ }_{2}$ groups in D1. For example, the dihedral angle of $\mathrm{C}_{4}-\mathrm{C}_{3}-\mathrm{N}_{2}-\mathrm{C}_{2}$ for D1-D3 is calculated to be $29.3^{\circ}, 32.4^{\circ}$, and $37.1^{\circ}$, respectively. Note that the dihedral angle of $\mathrm{C}_{4}-\mathrm{C}_{3}-\mathrm{N}_{2}-\mathrm{C}_{2}$ increases from $37.1^{\circ}$ (D3) to $43.3^{\circ}$ (D4) by introducing the $\mathrm{CF}_{3}$ group at the end of triphenylamine. Obviously, the steric obstruction can be justified by proper functional group and thus avoids the unfavorable dye aggregation on the $\mathrm{TiO}_{2}$ surface. Besides the dihedral angle of $\mathrm{C}_{4}-\mathrm{C}_{3}-\mathrm{N}_{2}-\mathrm{C}_{2}$, the bond length $\mathrm{C}_{1}-\mathrm{N}_{1}$ between the $\mathrm{D}$ and $\pi$ part increases in the following order: D4 $(1.408 \AA)<\mathrm{D} 3$ $(1.412 \AA)<\mathrm{D} 2(1.413 \AA)<\mathrm{D} 1(1.416 \AA)$, indicating the bond conjugation ability decreases in the same order. This can be explained by the $\mathrm{NBO}$ charges on the $\mathrm{C}_{1}$ and $\mathrm{N}_{1}$ atoms. The NBO charges on $\mathrm{N}_{1}$ atom of D2-D4 are similar with D1. But for $\mathrm{C}_{1}$ atom, it decreases dramatically in the following order: D4 $(0.148 \mathrm{e})>\mathrm{D} 3(0.133 \mathrm{e})>\mathrm{D} 2(0.127 \mathrm{e})>\mathrm{D} 1(0.117 \mathrm{e})$, suggesting the bond conjugation ability has been enhanced by introducing $\mathrm{N}$ (phenyl) ${ }_{2}$ and $\mathrm{CF}_{3}$ substitutions.

3.1. Frontier Molecular Orbital Analysis. The energy levels of the HOMO and LUMO, as well as the HOMO-LUMO gaps, are drawn in Figure 3, together with the energy levels of $\mathrm{TiO}_{2}$ semiconductor conduction band $(-4.00 \mathrm{eV})[34]$ and the redox potential of $\mathrm{I}^{-} / \mathrm{I}_{3}{ }^{-}(-4.80 \mathrm{eV})$ [35].

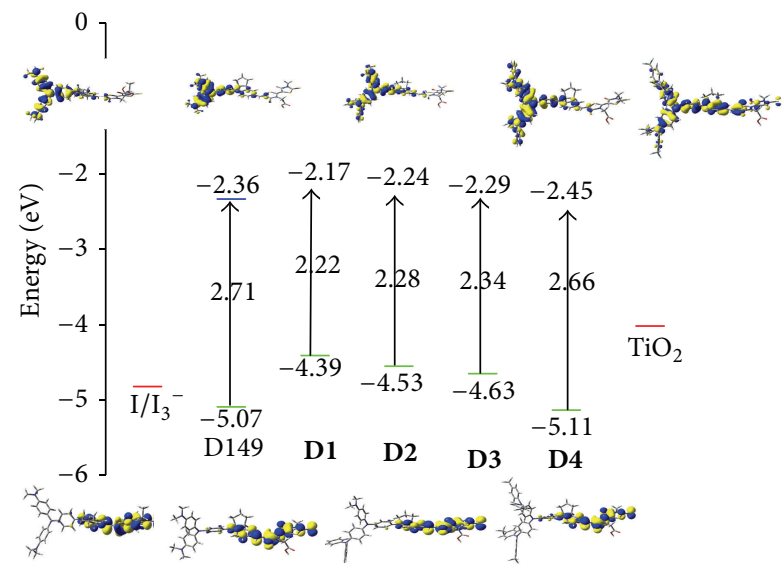

Figure 3: The energy levels and contour plot of HOMO and LUMO, as well as HOMO-LUMO energy gap (eV) of D149 and D1-D4. The redox potential of $\mathrm{I}^{-} / \mathrm{I}_{3}{ }^{-}(-4.80 \mathrm{eV})$ and energy level of conduction band $(\mathrm{CB})$ of the $\mathrm{TiO}_{2}$ surface $(-4.00 \mathrm{eV})$ are drawn in red line.

As drawn in Figure 3, the HOMO and LUMO energy levels of D1-D3 increase remarkably $(-4.39 \mathrm{eV}$ and $-2.17 \mathrm{eV}$ for D1, $-4.53 \mathrm{eV}$ and $-2.24 \mathrm{eV}$ for D2, and $-4.63 \mathrm{eV}$ and $-2.29 \mathrm{eV}$ for D3) compared with D149 obtained by us $(-5.07 \mathrm{eV}$ and $-2.36 \mathrm{eV})$ and previous work [24] $(-5.009 \mathrm{eV}$ and $-2.408 \mathrm{eV})$, which means that the energy level of molecular orbital can be greatly changed by introduction of triphenylamine into 


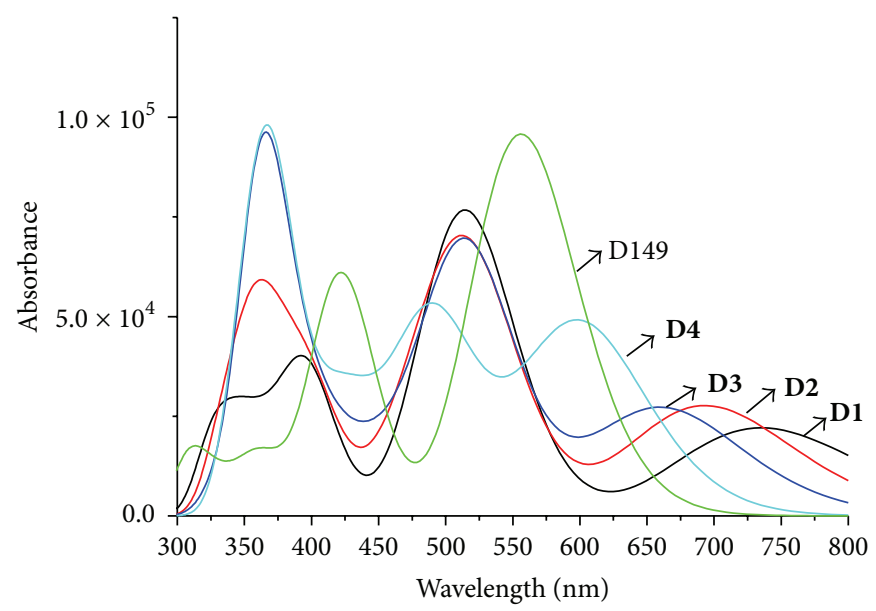

FIGURE 4: Simulated absorption spectra for D149 and D1-D4 obtained by B3LYP/6-31G* method in methanol media.

the donor part. Although the introduction of triphenylamine unit increases the HOMO values relative to D149, the HOMO level of D1-D3 still approaches the redox potential of $\mathrm{I}^{-} / \mathrm{I}_{3}{ }^{-}$ $(-4.80 \mathrm{eV})$. The HOMO level of $\mathbf{D} 4(-5.11 \mathrm{eV})$ decreases dramatically by importing the $\mathrm{CF}_{3}$ group at the end of the triphenylamine group, which is lower by $0.31 \mathrm{eV}$ than $\mathrm{I}^{-} / \mathrm{I}_{3}{ }^{-}$redox potential. This means that the studied dyes ensure efficient dye regeneration. In addition, the LUMO energy of D1-D4 is higher than the conduction band edge of $\mathrm{TiO}_{2}$, which would provide enough driving force for electron injection for ultrafast excited-state electron injection [36]. Thus, it is a good approach to enhance the ability of dye regeneration by introducing the $\mathrm{N}\left(\mathrm{CH}_{3}\right)_{2}$ and $\mathrm{N}$ (phenyl) substitutions at the donor part, especially for $\mathrm{CF}_{3}$ group. With the dramatically stabilized HOMO energy, the HOMOLUMO energy gap of these dyes increases in the following order: D1 $(2.22 \mathrm{eV})<\mathbf{D} 2(2.28 \mathrm{eV})<\mathbf{D} 3(2.34 \mathrm{eV})<\mathbf{D} 4$ $(2.66 \mathrm{eV})$. The energy gaps of our designed dyes D1-D3 are much smaller than the famous D149. As reported by previous work [37, 38], the sensitizers that have smaller energy gap values may show higher efficiency in the DSSCs. Thus, it can be inferred that our designed molecules may have improved light harvesting ability.

As drawn in Figure 3, the electron densities of the HOMO of D149 is mainly located on the donor part and indoline ring; the electron densities of its LUMO are mainly distributed around the $\pi$ group. It suggests that the HOMO to LUMO transition is a good charge separated state. The electron distributions of the HOMOs and LUMOs for D1-D4 have the similar features. Both the HOMOs and LUMOs of D1D4 possess $\pi$ and $\pi^{*}$ orbital delocalization. Therefore, it can be confirmed that the intramolecular charge transfer (ICT) may occur when electron excitation occurs from the HOMO to LUMO in these dyes.

3.2. The Absorption Spectra. On the basis of the optimized ground state geometries, the absorption spectra of dyes are calculated by TDDFT/B3LYP method with PCM in methanol media. The simulated electronic absorption spectra are depicted in Figure 4, and the corresponding absorption data are collected in Table 1.

Figure 4 shows the absorption spectrum of D1-D3 displaying three major absorption bands in their UV/Vis spectra, the lowest energy absorption band (in the region of 600.0-800.0 nm), lower energy absorption band (in the region of 450.0 to $600.0 \mathrm{~nm}$ ), and higher energy absorption band (in the region of 300.0 to $450.0 \mathrm{~nm}$ ). Compared with D1-D3, the absorption spectra of D4 are different in the band locations and intensity, due to importing the electronwithdrawing $\mathrm{CF}_{3}$ groups. From Figure 4 and Table 1, the lowest lying distinguishable absorption speak $\left(S_{1}\right)$ of these dyes exhibits dramatically blue shift tendency: D1 $(735.1 \mathrm{~nm})>$ D2 $(693.5 \mathrm{~nm})>$ D3 $(661.5 \mathrm{~nm})>$ D4 $(600.2 \mathrm{~nm})>$ D149 $(556.1 \mathrm{~nm})$, which is closely related to the increased HOMOLUMO energy gaps of these compounds (see Figure 3). Based on the analysis of electron density of HOMO and LUMO (see Section 3.2), all of the absorption behaviors of the $S_{1}$ can be ascribed to the intramolecular charge transfer (ICT) character. The maximum absorption speak of D1 and D2 is located at 517.5 and $518.7 \mathrm{~nm}$, respectively, which is contributed by HOMO-1 $\rightarrow$ LUMO transition. The HOMO-1 of D1 and D2 is contributed by $23.1 \%(\mathrm{D})+76.8 \%(\pi)$ and $53.4 \%(\mathrm{D})+$ $42.6 \%(\pi)$, respectively. Thus it is reasonable to assign the 517.5 and $518.7 \mathrm{~nm}$ for D1 and D2 to ICT character. For D3, the absorption speak with the largest oscillator strength is located at $515.7 \mathrm{~nm}$, which is contributed by HOMO-2 $\rightarrow$ LUMO transition. The HOMO-2 of D3 is focused on 99.9\% (D); therefore, the $515.7 \mathrm{~nm}$ of D3 still displays ICT character. With respect to $\mathbf{D} 4$, the absorption at 491.5 (attributed by HOMO-1 $\rightarrow$ LUMO) and $371.3 \mathrm{~nm}$ (attributed by HOMO $\rightarrow$ LUMO+4) are assigned to ICT character. The high-energy absorption speak for D1-D4 is located at 398.5, 362.2, 365.6, and $346.6 \mathrm{~nm}$, respectively, which is ascribed to $19.9 \%(\mathrm{D})+$ $79.4 \%(\pi) \rightarrow 98.2 \%(\pi), 85.1 \%(\mathrm{D})+14.5 \%(\pi) \rightarrow 20.8 \%$ (D) $+57.9 \%(\pi)+21.3 \%(A), 86.9 \%(D)+13.1 \%(\pi) \rightarrow 77.1 \%$ $(\mathrm{D})+21.2 \%(\pi)$, and $58.7 \%(\mathrm{D})+41.1 \%(\pi) \rightarrow 83.2 \%(\mathrm{D})+$ $16.4 \%(\pi)$ transitions with the ICT character.

From the above calculations, it can be seen that all the absorption speaks of D1-D4 are covering the entire visible 
TABLE 1: The calculated absorption wavelength $\lambda(\mathrm{nm})$, excitation energy $(\mathrm{eV})$, oscillator strength $(f>0.2)$, major configuration, and transition nature for D149 and D1-D4 (H, L, D, $\pi$, and A denote the HOMO, LUMO, triphenylamine moiety, indoline and rhodanine group, and $\mathrm{CH}_{2} \mathrm{COOH}$, resp.).

\begin{tabular}{|c|c|c|c|c|c|c|}
\hline & & $\lambda(\mathrm{nm})$ & $E(\mathrm{eV})$ & $f$ & Major configuration & Character \\
\hline \multirow{3}{*}{ D149 } & S1 & 556.1 & 2.23 & 1.3220 & $99 \% \mathrm{H} \rightarrow \mathrm{L}$ & $30.12 \%(D)+69.8 \%(\pi) \rightarrow 95.5 \%(\pi)$ \\
\hline & S2 & 425.8 & 2.91 & 0.6637 & $70 \% \mathrm{H}-1 \rightarrow \mathrm{L}$ & $40.1 \%(D)+59.4 \%(\pi) \rightarrow 95.5 \%(\pi)$ \\
\hline & S3 & 410.5 & 3.02 & 0.2097 & $67 \% \mathrm{H} \rightarrow \mathrm{L}+1$ & $30.1 \%(D)+69.8 \%(\pi) \rightarrow 51.8 \%(D)+47.7 \%(\pi)$ \\
\hline \multirow{4}{*}{ D1 } & S1 & 735.1 & 1.69 & 0.3047 & $100 \% \mathrm{H} \rightarrow \mathrm{L}$ & $87.2 \%(\mathrm{D}) \rightarrow 98.2 \%(\pi)$ \\
\hline & S2 & 517.5 & 2.40 & 0.9613 & $99 \% \mathrm{H}-1 \rightarrow \mathrm{L}$ & $23.1 \%(\mathrm{D})+76.8 \%(\pi) \rightarrow 98.2 \%(\pi)$ \\
\hline & S5 & 398.5 & 3.11 & 0.4368 & $69 \% \mathrm{H}-3 \rightarrow \mathrm{L}$ & $19.9 \%(D)+79.4 \%(\pi) \rightarrow 98.2 \%(\pi)$ \\
\hline & S13 & 327.7 & 3.78 & 0.2404 & $78 \% \mathrm{H} \rightarrow \mathrm{L}+6$ & $87.2 \%(\mathrm{D}) \rightarrow 57.8 \%(\pi)+39.1 \%(\mathrm{~A})$ \\
\hline \multirow{5}{*}{ D2 } & S1 & 693.5 & 1.79 & 0.3812 & $99 \% \mathrm{H} \rightarrow \mathrm{L}$ & $85.1 \%(\mathrm{D})+14.5 \%(\pi) \rightarrow 90.9 \%(\pi)$ \\
\hline & S2 & 518.7 & 2.39 & 0.8282 & $91 \% \mathrm{H}-1 \rightarrow \mathrm{L}$ & $53.4 \%(\mathrm{D})+42.6 \%(\pi) \rightarrow 90.9 \%(\pi)$ \\
\hline & S4 & 469.6 & 2.64 & 0.2039 & $97 \% \mathrm{H} \rightarrow \mathrm{L}+1$ & $85.1 \%(D)+14.5 \%(\pi) \rightarrow 92.8 \%(\pi)$ \\
\hline & S5 & 402.7 & 3.08 & 0.3328 & $85 \% \mathrm{H}-3 \rightarrow \mathrm{L}$ & $24.9 \%(D)+65.6 \%(\pi) \rightarrow 90.9 \%(\pi)$ \\
\hline & S10 & 362.4 & 3.42 & 0.3017 & $61 \% \mathrm{H} \rightarrow \mathrm{L}+4$ & $85.1 \%(\mathrm{D})+14.5 \%(\pi) \rightarrow 20.8 \%(\mathrm{D}) 57.9 \%(\pi)+21.3 \%(\mathrm{~A})$ \\
\hline \multirow{5}{*}{ D3 } & $\mathrm{S} 1$ & 661.5 & 1.87 & 0.3729 & $99 \% \mathrm{H} \rightarrow \mathrm{L}$ & $86.9 \%(\mathrm{D})+13.1 \%(\pi) \rightarrow 97.2 \%(\pi)$ \\
\hline & S2 & 515.7 & 2.40 & 0.9305 & $98 \% \mathrm{H}-2 \rightarrow \mathrm{L}$ & $99.9 \%(D) \rightarrow 97.2 \%(\pi)$ \\
\hline & S10 & 365.6 & 3.39 & 0.5877 & $92 \% \mathrm{H} \rightarrow \mathrm{L}+4$ & $86.9 \%(D)+13.1 \%(\pi) \rightarrow 77.1 \%(D)+21.2 \%(\pi)$ \\
\hline & S11 & 363.8 & 3.41 & 0.2335 & $57 \% \mathrm{H}-4 \rightarrow \mathrm{L}$ & $44.0 \%(D)+55.3 \% \rightarrow 97.2 \%(\pi)$ \\
\hline & S12 & 353.9 & 3.50 & 0.2481 & $47 \% \mathrm{H} \rightarrow \mathrm{L}+2$ & $86.9 \%(D)+13.1 \%(\pi) \rightarrow 96.2 \%(D)$ \\
\hline \multirow{6}{*}{ D4 } & S1 & 600.2 & 2.07 & 0.6676 & $99 \% \mathrm{H} \rightarrow \mathrm{L}$ & $58.7 \%(\mathrm{D})+41.1 \%(\pi) \rightarrow 96.4 \%(\pi)$ \\
\hline & S2 & 491.5 & 2.52 & 0.7025 & $98 \% \mathrm{H}-1 \rightarrow \mathrm{L}$ & $46.0 \%(D)+53.6 \%(\pi) \rightarrow 96.4 \%(\pi)$ \\
\hline & S4 & 427.9 & 2.90 & 0.3875 & $91 \% \mathrm{H} \rightarrow \mathrm{L}+1$ & $58.7 \%(\mathrm{D})+41.1 \%(\pi) \rightarrow 89.2 \%(\pi)$ \\
\hline & S7 & 371.3 & 3.34 & 0.7061 & $90 \% \mathrm{H} \rightarrow \mathrm{L}+4$ & $58.7 \%(D)+41.1 \%(\pi) \rightarrow 99.6 \%(D)$ \\
\hline & S12 & 357.1 & 3.47 & 0.2167 & $53 \% \mathrm{H}-4 \rightarrow \mathrm{L}$ & $99.9 \%(\pi) \rightarrow 96.4 \%(\pi)$ \\
\hline & S13 & 346.6 & 3.58 & 0.2581 & $64 \% \mathrm{H} \rightarrow \mathrm{L}+6$ & $58.7 \%(\mathrm{D})+41.1 \%(\pi) \rightarrow 83.2 \%(\mathrm{D})+16.4 \%(\pi)$ \\
\hline
\end{tabular}

region, which makes these dyes suitable for the application of DSSCs. The location and intensity of the absorption band of these dyes are greatly affected by introducing the $\mathrm{N}\left(\mathrm{CH}_{3}\right)_{2}$, $\mathrm{N}$ (phenyl) ${ }_{2}$, and $\mathrm{CF}_{3}$ groups, which means the photophysical properties can be well tuned by proper substitutions. All the intense absorption bands of D1-D4 correspond to the ICT transition, which will play an important role in conversion efficiencies.

3.3. Photoelectric Conversion Efficiency of Dyes. Rapid electron injection from the photoinduced excited states of dyes to the $\mathrm{TiO}_{2}$ is desired for high performance of DSSCs. According to Preat's method [33], the driving force $\Delta G_{\text {inject }}$ of electrons injections from the excited states of dyes to semiconductor surface is calculated and the results are drawn in Figure 5.

Figure 5 shows that all the $\Delta G_{\text {inject }}$ values are very negative (in the region of $-1.55--1.86 \mathrm{eV}$ ), which suggests that the dye excited state lies above the $\mathrm{TiO}_{2}$ conduction band edge. Therefore, it is favorable for electron injection from the excited state dye to the $\mathrm{TiO}_{2}$ conduction band edge. Compared with D149 $(-1.08 \mathrm{eV}), \mathrm{D1}-\mathrm{D} 4$ have much more negative $\Delta G_{\text {inject }}$ values. As expected, the electron injection ability has been improved by replacing the donor part of D149 by triphenylamine. Furthermore, the $\Delta G_{\text {inject }}$ values of D2 and D3 are $-1.74 \mathrm{eV}$ and $1.66 \mathrm{eV}$, respectively, which are much more positive than $\mathrm{D} 1(-1.86 \mathrm{eV})$, indicating that the introduction

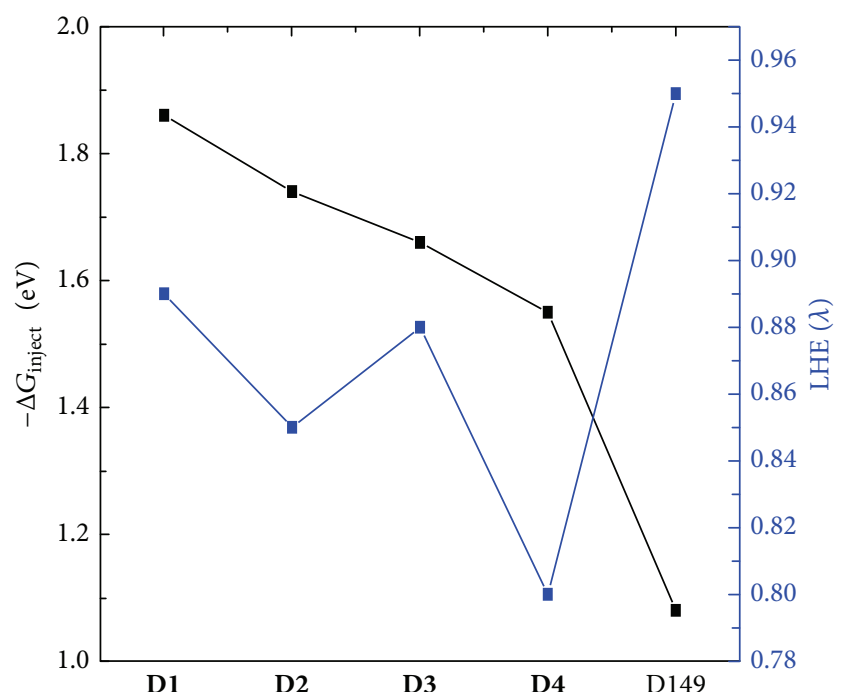

FIGURE 5: The calculated $-\Delta G_{\text {inject }}$ (in $\mathrm{eV}$ ) and $\operatorname{LHE}(\lambda)$ of studied complexes.

of diphenylamine at the end of triphenylamine unit results in destabilization of the oxidized dye and therefore reduces the electron injection. In addition, $\Delta G_{\text {inject }}$ value of $\mathbf{D} 4$ $(-1.55 \mathrm{eV})$ is positive than that of $\mathbf{D} 3$, indicating it would not 


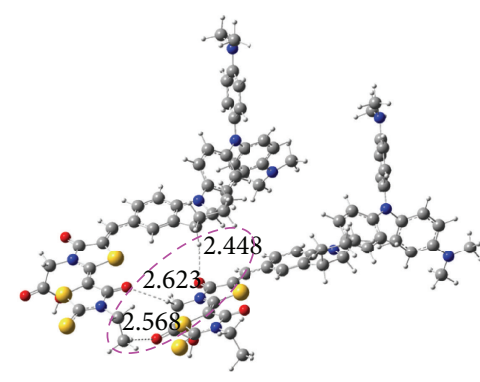

(a)

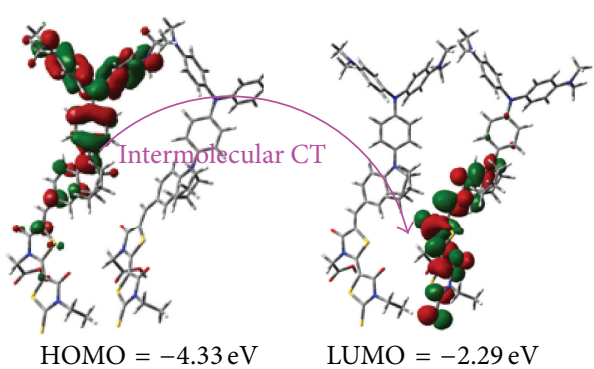

(b)

FIGURE 6: (a) The optimized ground geometry of D1 dimer and (b) its HOMO and LUMO orbital. The H $\cdots$ O bond length ( $\AA$ ) is labeled in the optimized geometry.

be favorable to enhance the electron injection by importing the $\mathrm{CF}_{3}$ group at the end of phenylamine. According to (3) in Section 2, the $\operatorname{LHE}(\lambda)$ of studied complexes are calculated and the results are also drawn in Figure 5. As depicted in Figure 5, the D1 has larger $\operatorname{LHE}(\lambda)$ than D2-D4, which means that D1 has more efficient light harvesting capability than others. As discussed in Section 2, the large values of $\Delta G_{\text {inject }}$ and $\operatorname{LHE}(\lambda)$ are possible approaches to maximize the short-circuit $\left(J_{s c}\right)$. Consequently, it is a promising approach to enhance the efficiency by introducing the $\mathrm{N}\left(\mathrm{CH}_{3}\right)_{2}$ group at the donor part.

3.4. Structures and Properties of Dye Dimers. The intermolecular interactions of these dyes dimer are investigated by B3LYP method to predict the stabilization upon dye aggregation. Figure 6 illustrates the optimized geometries of D1 dimer. Further survey of the HOMO and LUMO orbitals of D1 dimer is also collected in Figure 6. The properties of D2-D3 dimers are given in Figure S1 in the supporting information (see Supplementary Material available online at http://dx.doi.org/10.1155/2015/605728).

As shown in Figure 6 and Figure S1, all these stable molecules have formed intermolecular $\mathrm{H} \cdots \mathrm{O}$ hydrogen bonds. Take D1 dimer as an example, the carboxyl and terminal carbonyl group of thiazolidine form three $\mathrm{H} \cdots \mathrm{O}$ hydrogen bonds. One $\mathrm{H} \cdots \mathrm{O}$ hydrogen bond is $2.568 \AA$, which is formed by the carboxyl and one terminal $\mathrm{H}$ atoms in the ethyl. Another two $\mathrm{H} \cdots \mathrm{O}$ hydrogen bonds are 2.623 and $2.448 \AA$, which are formed by the two $\mathrm{O}$ atoms in the carbonyl group of thiazolidines interact with the two $\mathrm{H}$ atoms. In addition, the HOMOs of dimers are mainly located on one monomer, while their LUMO are contributed by another monomeric unit. Clearly, the intermolecular charge transfer process between the dyes dimers may occur for all the dyes. Compared with the isolated dye monomer (see Figure 3), the HOMO energy of D1 dimer slightly increases by $0.06 \mathrm{eV}$, while the LUMO energy decreases by $0.12 \mathrm{eV}$, respectively. Because of the dramatically decreased LUMO energy, the HOMO-LUMO energy gap of D1 dimer becomes narrowed $0.18 \mathrm{eV}$ compared with monomer. Similarly, the HOMO-LUMO energy gap of D2 dimer and D3 dimer decreases by $0.14 \mathrm{eV}$ and $0.18 \mathrm{eV}$, respectively, compared with corresponding monomer. Normally, the narrowed HOMOLUMO energy gap favors red shifted of absorption spectra.
As reported by Pastore and De Angelis [13], the red-shift of absorption spectra for indoline dye are due to the dye aggregation. Therefore dye aggregation is expected to be associated with the HOMO-LUMO energy gap of dye dimer. Since there are small differences of HOMO-LUMO energy gap of these dimers compared with corresponding monomer, introducing the $\mathrm{N}$ (phenyl) $)_{2}$ substitutions at the donor may play a slightl effect on avoiding unfavorable dye aggregation.

3.5. Dye- $\left(\mathrm{TiO}_{2}\right)_{6}$ Complexes. For a better understanding of the effect of the triphenylamine-based donor on the electron coupling, these dyes bound to $\left(\mathrm{TiO}_{2}\right)_{6}$ cluster are optimized by B3LYP method. As well accepted, there are two common absorption models for dyes absorbed on the surface $[39,40]$. One is a single Ti-O monodentate binding mode; another is a bidentate chelating structure mode. In this work, we take D4 as an example to testify which mode is stable absorption configuration. The optimized geometries of $\mathbf{D} 4-\left(\mathrm{TiO}_{2}\right)_{6}$ in different models are drawn in Figure S2. It can be seen that the total energy of bidentate-chelating configuration is lower $3.75 \mathrm{kcal} / \mathrm{mol}$ than single monodentate mode. This agrees with the previous work; that is, the bidentate chelating structure mode is usually predicted to be stable [13, 41-43]. Therefore, the D149 and D1-D3 absorbed on the surface are optimized under the bidentate chelating structure mode. The optimized geometry, absorption energies $\left(E_{\mathrm{ads}}\right)$, and the contour plot of the HOMO and LUMO of dye- $\left(\mathrm{TiO}_{2}\right)_{6}$ complexes are depicted in Figure 7. The energy level of frontier molecule orbital $(\mathrm{eV})$ of the dye- $\left(\mathrm{TiO}_{2}\right)_{6}$ and the energies differences between the dye and dye- $\left(\mathrm{TiO}_{2}\right)_{6}$ are drawn in Figure 8.

As shown in Figure 7, the decreased order of $E_{\text {abs }}$ for D149 and D1-D4 is D149 $(23.68 \mathrm{kcal} / \mathrm{mol})>$ D1 $(20.81 \mathrm{kcal} / \mathrm{mol})>$ D2 $(15.66 \mathrm{kcal} / \mathrm{mol})>$ D3 $(10.32 \mathrm{kcal} / \mathrm{mol})>$ D4 $(2.85 \mathrm{kcal} /$ $\mathrm{mol}$ ), indicating the interactions between the dye and $\mathrm{TiO}_{2}$ surface is decreasing in the same order. In particular, for $\mathbf{D 4}$, the $E_{\mathrm{abs}}$ is so small that $\mathbf{D} 4$ is difficult to be chemisorbed on the cluster. After absorption to the $\left(\mathrm{TiO}_{2}\right)_{6}$ cluster, the calculated distances of D1 between the carboxylic oxygen atoms and the $\left(\mathrm{TiO}_{2}\right)_{6}$ cluster ( $\mathrm{Ti}-\mathrm{O}$ bond lengths) are about $2.032 \AA$ and $2.115 \AA$. By introducing the $\mathrm{N}(\text { phenyl })_{2}$ and $\mathrm{CF}_{3}$ groups, the two Ti-O bond lengths increase to $2.032 \AA$ and $2.116 \AA$ for D2, $2.032 \AA$ and $2.117 \AA$ for D3, and $2.032 \AA$ and $2.119 \AA$ for $\mathrm{D} 4$. It suggests that the $\mathrm{N}(\text { phenyl })_{2}$ and $\mathrm{CF}_{3}$ groups 


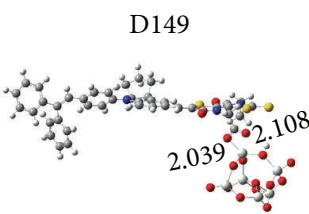

$E_{\mathrm{ads}}=23.69 \mathrm{kcal} / \mathrm{mol}$
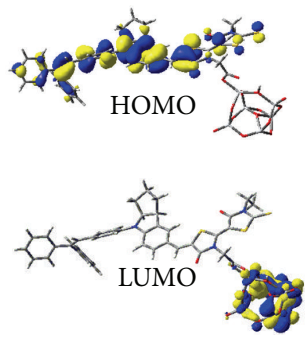

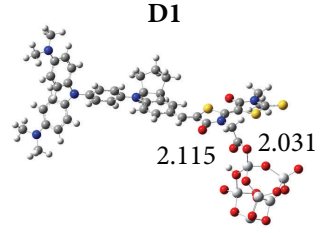

$E_{\mathrm{ads}}=20.81 \mathrm{kcal} / \mathrm{mol}$

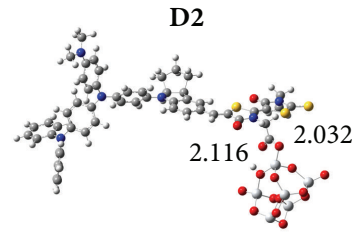

$E_{\text {ads }}=15.66 \mathrm{kcal} / \mathrm{mol}$

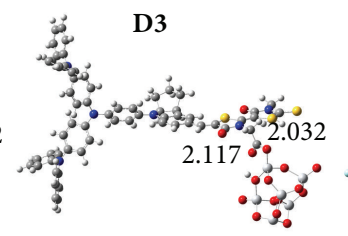

$E_{\text {ads }}=10.32 \mathrm{kcal} / \mathrm{mol}$

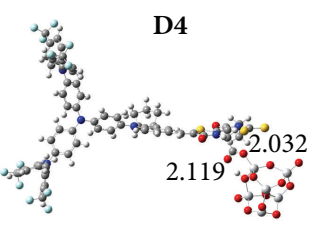

$E_{\text {ads }}=2.85 \mathrm{kcal} / \mathrm{mol}$
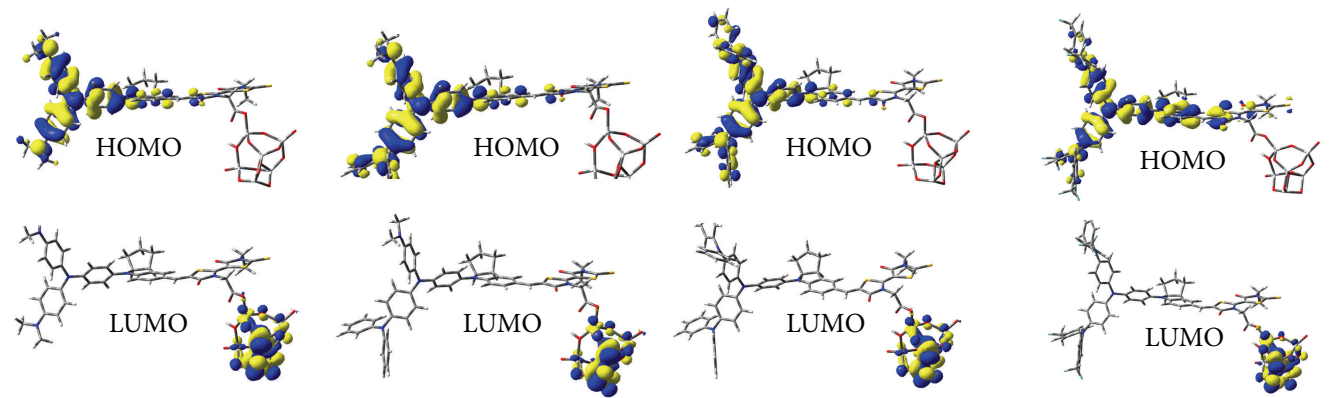

FIGURE 7: Optimized geometries, absorption energies ( $\mathrm{kcal} / \mathrm{mol})$, and contour plot of HOMO and LUMO of studied molecule absorbed on the $\left(\mathrm{TiO}_{2}\right)_{6}$ cluster.

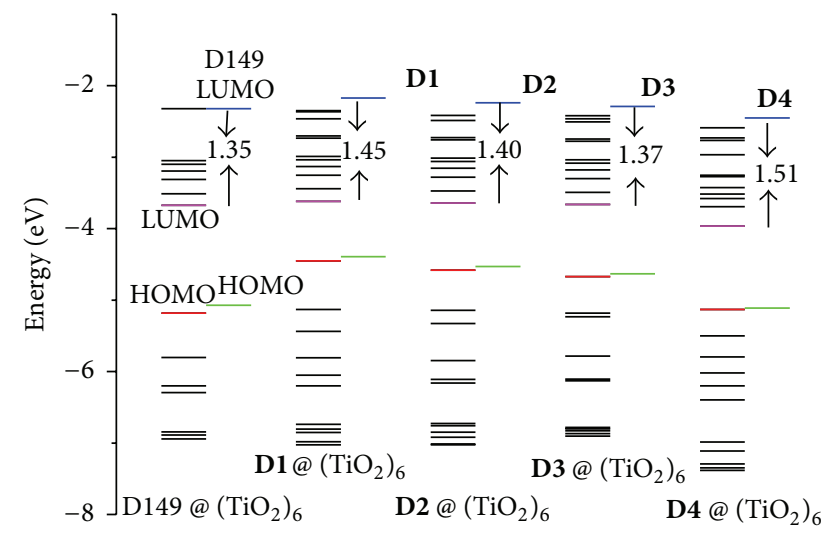

Figure 8: The energy diagram of frontier molecule orbital (eV) of the dye- $\left(\mathrm{TiO}_{2}\right)_{6}$, as well as the HOMO and LUMO energy of dyes.

have decreased the electron coupling between the dyes and surface, which is consistent with the analyses of $E_{\text {ads }}$.

Molecular orbital spatial distribution shows that the HOMO of dye- $\left(\mathrm{TiO}_{2}\right)_{6}$ is mainly localized over the donor part of dyes, while the LUMO is focused on the $\left(\mathrm{TiO}_{2}\right)_{6}$ part. As expected, the interfacial electron injection from the dye to the $\mathrm{TiO}_{2}$ surface may successively transfer when the dyes bind on the $\mathrm{TiO}_{2}$ film. Furthermore, compared with the isolated sensitizer, the HOMOs have subtle changes (about $0.1 \mathrm{eV}$ ) when the D149 and D1-D4 absorb to $\left(\mathrm{TiO}_{2}\right)_{6}$ cluster. The most noticeable difference between the isolated dyes and dye- $\left(\mathrm{TiO}_{2}\right)_{6}$ is focused on the LUMO energy. The LUMO energy of (D1-D4)- $\left(\mathrm{TiO}_{2}\right)_{6}$ dramatically decreases compared with D149-( $\left(\mathrm{TiO}_{2}\right)_{6}$, suggesting that the LUMOs of all designed dyes create relative strong electronic coupling with $\mathrm{TiO}_{2}$ film and, as a result, further boost the electron injection. In addition, the LUMO of D1- $\left(\mathrm{TiO}_{2}\right)_{6}$ is lower $1.45 \mathrm{eV}$ than that of $\mathbf{D} 1$. While the lower-lying energy LUMO of D149- $\left(\mathrm{TiO}_{2}\right)_{6}(1.35 \mathrm{eV})$, D2- $\left(\mathrm{TiO}_{2}\right)_{6}(1.40 \mathrm{eV})$, and D3$\left(\mathrm{TiO}_{2}\right)_{6}(1.37 \mathrm{eV})$ becomes smaller than that of $\mathrm{D} 1$, indicating that the electronic coupling to the $\mathrm{TiO}_{2}$ surface decreases by importing the $\mathrm{N}$ (phenyl) ${ }_{2}$.

\section{Conclusions}

The electronic structures, absorption spectra, and photophysical properties of triphenylamine-based indoline dyes as photosensitizers for application in DSSCs were investigated by density functional theory (DFT) and time-dependent DFT (TD-DFT). The calculated results demonstrated that the donor parts had great effect on the structure and optical properties. Compared with D149, D1-D3 had proper HOMO and LUMO energy level as well as narrow HOMO-LUMO energy gap by introducing the $\mathrm{N}\left(\mathrm{CH}_{3}\right)_{2}$ and $\mathrm{N}(\text { phenyl })_{2}$ groups at the donor part; therefore D1-D3 may be good DSSC sensitizers. The absorption speaks of D1-D4 covered the entire visible region and the intense absorption bands of them all corresponded to the intramolecular charge transfer transition, which may play an important role in conversion efficiencies. The stable molecule of D1-D3 dimmers were formed by intermolecular $\mathrm{H} \cdots \mathrm{O}$ hydrogen bonds. The data of $E_{\text {abs }}$ and the LUMO energy level of dye- $\left(\mathrm{TiO}_{2}\right)_{6}$ suggested that D1 had the strongest interactions between the dye and $\mathrm{TiO}_{2}$ surface of these dyes. Furthermore, D1 had larger $\Delta G_{\text {inject }}$ and $\operatorname{LHE}(\lambda)$ values than D2-D4, indicating that D1 may have improved energy conversion efficiency by introducing the $\mathrm{N}\left(\mathrm{CH}_{3}\right)_{2}$ group at the donor part of triphenylamine. We hope that this work will be helpful for designing the organic dyes with high efficiency.

\section{Conflict of Interests}

The authors declare that there is no conflict of interests regarding the publication of this paper. 


\section{Acknowledgments}

Financial supports were received from NSFC (no. 21243006 and 51304193), the Basic Research Program of Jiangsu Province (no. BK20130172), and the Fundamental Research Funds for the Central Universities (nos. 2013QNA14 and 2010QNA10). A Project funded by the Priority Academic Program Development of Jiangsu Higher Education Institutions is acknowledged. The authors are grateful to the High Performance Computing Center of China University of Mining and Technology for the award of CPU hours to accomplish this work.

\section{References}

[1] B. O'Reagen and M. Grätzel, "A low-cost, high-efficiency solar cell based on dye-sensitized colloidal $\mathrm{TiO}_{2}$ films," Nature, vol. 353, pp. 737-740, 1991.

[2] M. Grätzel, "Solar energy conversion by dye-sensitized photovoltaic cells," Inorganic Chemistry, vol. 44, no. 20, pp. 6841-6851, 2005.

[3] M. K. Nazeeruddin, A. Kay, I. Rodicio et al., "Conversion of light to electricity by cis-X2bis $\left(2,2^{\prime}\right.$-bipyridyl- $4,4^{\prime}$-dicarboxylate)ruthenium(II) charge-transfer sensitizers ( $\mathrm{X}=\mathrm{Cl}-, \mathrm{Br}-$, I-, $\mathrm{CN}-$, and $\mathrm{SCN}-$ ) on nanocrystalline titanium dioxide electrodes," Journal of the American Chemical Society, vol. 115, no. 14, pp. 6382-6390, 1993.

[4] M. K. Nazeeruddin, P. Péchy, T. Renouard et al., "Engineering of efficient panchromatic sensitizers for nanocrystalline $\mathrm{TiO}_{2}-$ based solar cells," Journal of the American Chemical Society, vol. 123, no. 8, pp. 1613-1624, 2001.

[5] S. Chang, H. Wang, L. T. Lin Lee et al., "Panchromatic light harvesting by N719 with a porphyrin molecule for highperformance dye-sensitized solar cells," Journal of Materials Chemistry C, vol. 2, no. 18, pp. 3521-3526, 2014.

[6] R. K. Kanaparthi, J. Kandhadi, and L. Giribabu, "Metal-free organic dyes for dye-sensitized solar cells: Recent advances," Tetrahedron, vol. 68, no. 40, pp. 8383-8393, 2012.

[7] Y. Wu and W. Zhu, "Organic sensitizers from D- $\pi-A$ to DA- $\pi-A$ : effect of the internal electron-withdrawing units on molecular absorption, energy levels and photovoltaic performances," Chemical Society Reviews, vol. 42, pp. 2039-2058, 2013.

[8] B.-G. Kim, K. Chung, and J. Kim, "Molecular design principle of all-organic dyes for dye-sensitized solar cells," Chemistry: A European Journal, vol. 19, no. 17, pp. 5220-5230, 2013.

[9] G. B. Consiglio, F. Pedna, C. Fornaciari et al., "Assessment of new gem-silanediols as suitable sensitizers for dye-sensitized solar cells," Journal of Organometallic Chemistry, vol. 723, pp. 198-206, 2013.

[10] W. H. Howie, F. Claeyssens, H. Miura, and L. M. Peter, "Characterization of solid-state dye-sensitized solar cells utilizing high absorption coefficient metal-free organic dyes," Journal of the American Chemical Society, vol. 130, no. 4, pp. 1367-1375, 2008.

[11] S. Ito, H. Miura, S. Uchida et al., "High-conversion-efficiency organic dye-sensitized solar cells with a novel indoline dye," Chemical Communications, no. 41, pp. 5194-5196, 2008.

[12] M. K. Nazeeruddin, F. De Angelis, S. Fantacci et al., "Combined experimental and DFT-TDDFT computational study of photoelectrochemical cell ruthenium sensitizers," Journal of the American Chemical Society, vol. 127, no. 48, pp. 16835-16847, 2005.
[13] M. Pastore and F. De Angelis, "Aggregation of organic dyes on $\mathrm{TiO}_{2}$ in dye-sensitized solar cells models: an $\mathrm{Ab}$ initio investigation," ACS Nano, vol. 4, no. 1, pp. 556-562, 2010.

[14] H. Fukunishi, S. Nakamura, and S. Fujieda, "Influence of conformation on the absorption spectra of flexible organic dyes used in dye-sensitized solar cells," Computational and Theoretical Chemistry, vol. 1014, pp. 29-36, 2013.

[15] Q. Q. Li, L. L. Lu, C. Zhong et al., "New indole-based metalfree organic dyes for dye-sensitized solar cells," The Journal of Physical Chemistry B, vol. 113, no. 44, pp. 14588-14595, 2009.

[16] P. Liu, J.-J. Fu, M.-S. Guo, X. Zuo, and Y. Liao, "Effect of the chemical modifications of thiophene-based N3 dyes on the performance of dye-sensitized solar cells: a density functional theory study," Computational and Theoretical Chemistry, vol. 1015, pp. 8-14, 2013.

[17] S. Meng, E. Kaxiras, M. K. Nazeeruddin, and M. Grätzel, "Design of dye acceptors for photovoltaics from first-principles calculations," Journal of Physical Chemistry C, vol. 115, no. 18, pp. 9276-9282, 2011.

[18] W.-L. Ding, D.-M. Wang, Z.-Y. Geng, X.-L. Zhao, and Y.-F. Yan, "Molecular engineering of indoline-based D-A- $\pi$-A organic sensitizers toward high efficiency performance from firstprinciples calculations," Journal of Physical Chemistry C, vol. 117, no. 34, pp. 17382-17398, 2013.

[19] M. Liang and J. Chen, "Arylamine organic dyes for dyesensitized solar cells," Chemical Society Reviews, vol. 42, no. 8, p. 3453, 2013.

[20] W. Xu, B. Peng, J. Chen, M. Liang, and F. Cai, "New triphenylamine-based dyes for dye-sensitized solar cells," Journal of Physical Chemistry C, vol. 112, no. 3, pp. 874-880, 2008.

[21] M. Liang, W. Xu, F. Cai et al., "New triphenylamine-based organic dyes for efficient dye-sensitized solar cells," Journal of Physical Chemistry C, vol. 111, no. 11, pp. 4465-4472, 2007.

[22] H.-Q. Xia, J. Wang, F.-Q. Bai, and H.-X. Zhang, "Theoretical studies of electronic and optical properties of the triphenylamine-based organic dyes with diketopyrrolopyrrole chromophore," Dyes and Pigments, vol. 113, pp. 87-95, 2015.

[23] M. J. Frisch, G. W. Trucks, H. B. Schlegel et al., Gaussian 09, Revision B.04, Gaussian, Wallingford, Conn, USA, 2009.

[24] H. W. Ham and Y. S. Kim, "Theoretical study of indoline dyes for dye-sensitized solar cells," Thin Solid Films, vol. 518, no. 22, pp. 6558-6563, 2010.

[25] C. Lee, W. Yang, and R. G. Parr, "Development of the ColleSalvetti correlation-energy formula into a functional of the electron density," Physical Review B, vol. 37, no. 2, pp. 785-789, 1988.

[26] A. D. Becke, "Density-functional thermochemistry. III. The role of exact exchange," The Journal of Chemical Physics, vol. 98, no. 7, p. 5648, 1993.

[27] M. Cossi, G. Scalmani, N. Rega, and V. Barone, "New developments in the polarizable continuum model for quantum mechanical and classical calculations on molecules in solution," Journal of Chemical Physics, vol. 117, no. 1, pp. 43-54, 2002.

[28] V. Barone, M. Cossi, and J. Tomasi, "A new definition of cavities for the computation of solvation free energies by the polarizable continuum model," Journal of Chemical Physics, vol. 107, no. 8, pp. 3210-3221, 1997.

[29] R. Sánchez-De-Armas, J. Oviedo López, M. A. San-Miguel, J. F. Sanz, P. Ordejón, and M. Pruneda, "Real-time TD-DFT simulations in dye sensitized solar cells: the electronic absorption spectrum of alizarin supported on $\mathrm{TiO}_{2}$ nanoclusters," Journal 
of Chemical Theory and Computation, vol. 6, no. 9, pp. 28562865, 2010.

[30] M. R. Narayan, "Review: dye sensitized solar cells based on natural photosensitizers," Renewable and Sustainable Energy Reviews, vol. 16, no. 1, pp. 208-215, 2012.

[31] J.-Z. Zhang, H.-B. Li, Y. Wu et al., "Modulation on charge recombination and light harvesting toward high-performance benzothiadiazole-based sensitizers in dye-sensitized solar cells: a theoretical investigation," Journal of Power Sources, vol. 267, pp. 300-308, 2014.

[32] J. Zhang, H.-B. Li, S.-L. Sun, Y. Geng, Y. Wu, and Z.-M. Su, "Density functional theory characterization and design of highperformance diarylamine-fluorene dyes with different $\pi$ spacers for dye-sensitized solar cells," Journal of Materials Chemistry, vol. 22, no. 2, pp. 568-576, 2012.

[33] J. Preat, C. Michaux, D. Jacquemin, and E. A. Perpète, "Enhanced efficiency of organic dye-sensitized solar cells: triphenylamine derivatives," Journal of Physical Chemistry C, vol. 113, no. 38, pp. 16821-16833, 2009.

[34] M. Grätzel, "Photoelectrochemical cells," Nature, vol. 414, no. 6861, pp. 338-344, 2001.

[35] D. Cahen, G. Hodes, M. Grätzel, J. F. Guillemoles, and I. Riess, "Nature of photovoltaic action in dye-sensitized solar cells," Journal of Physical Chemistry B, vol. 104, no. 9, pp. 2053-2059, 2000.

[36] S. Meng and E. Kaxiras, "Electron and hole dynamics in dyesensitized solar cells: influencing factors and systematic trends," Nano Letters, vol. 10, no. 4, pp. 1238-1247, 2010.

[37] W. M. Campbell, K. W. Jolley, P. Wagner et al., "Highly efficient porphyrin sensitizers for dye-sensitized solar cells," Journal of Physical Chemistry C, vol. 111, no. 32, pp. 11760-11762, 2007.

[38] R. Ma, P. Guo, H. Cui, X. Zhang, M. K. Nazeeruddin, and M. Grätzel, "Substituent effect on the meso-substituted porphyrins: theoretical screening of sensitizer candidates for dye-sensitized solar cells," The Journal of Physical Chemistry A, vol. 113, no. 37, pp. 10119-10124, 2009.

[39] M. Nara, H. Torii, and M. Tasumi, "Correlation between the vibrational frequencies of the carboxylate group and the types of its coordination to a metal ion: an ab initio molecular orbital study," Journal of Physical Chemistry, vol. 100, no. 51, pp. 1981219817, 1996.

[40] G. B. Deacon and R. J. Phillips, "Relationships between the carbon-oxygen stretching frequencies of carboxylato complexes and the type of carboxylate coordination," Coordination Chemistry Reviews, vol. 33, no. 3, pp. 227-250, 1980.

[41] P. Chen, J. H. Yum, F. de Angelis et al., "High open-circuit voltage solid-state dye-sensitized solar cells with organic dye," Nano Letters, vol. 9, no. 6, pp. 2487-2492, 2009.

[42] H. Tian, X. Yang, R. Chen, R. Zhang, A. Hagfeldt, and L. Sun, "Effect of different dye baths and dye-structures on the performance of dye-sensitized solar cells based on triphenylamine dyes," Journal of Physical Chemistry C, vol. 112, no. 29, pp. 1102311033, 2008.

[43] M. Pastore and F. D. Angelis, "Computational modeling of stark effects in organic dye-sensitized $\mathrm{TiO}_{2}$ heterointerfaces," The Journal of Physical Chemistry Letters, vol. 2, no. 11, pp. 1261-1267, 2011. 

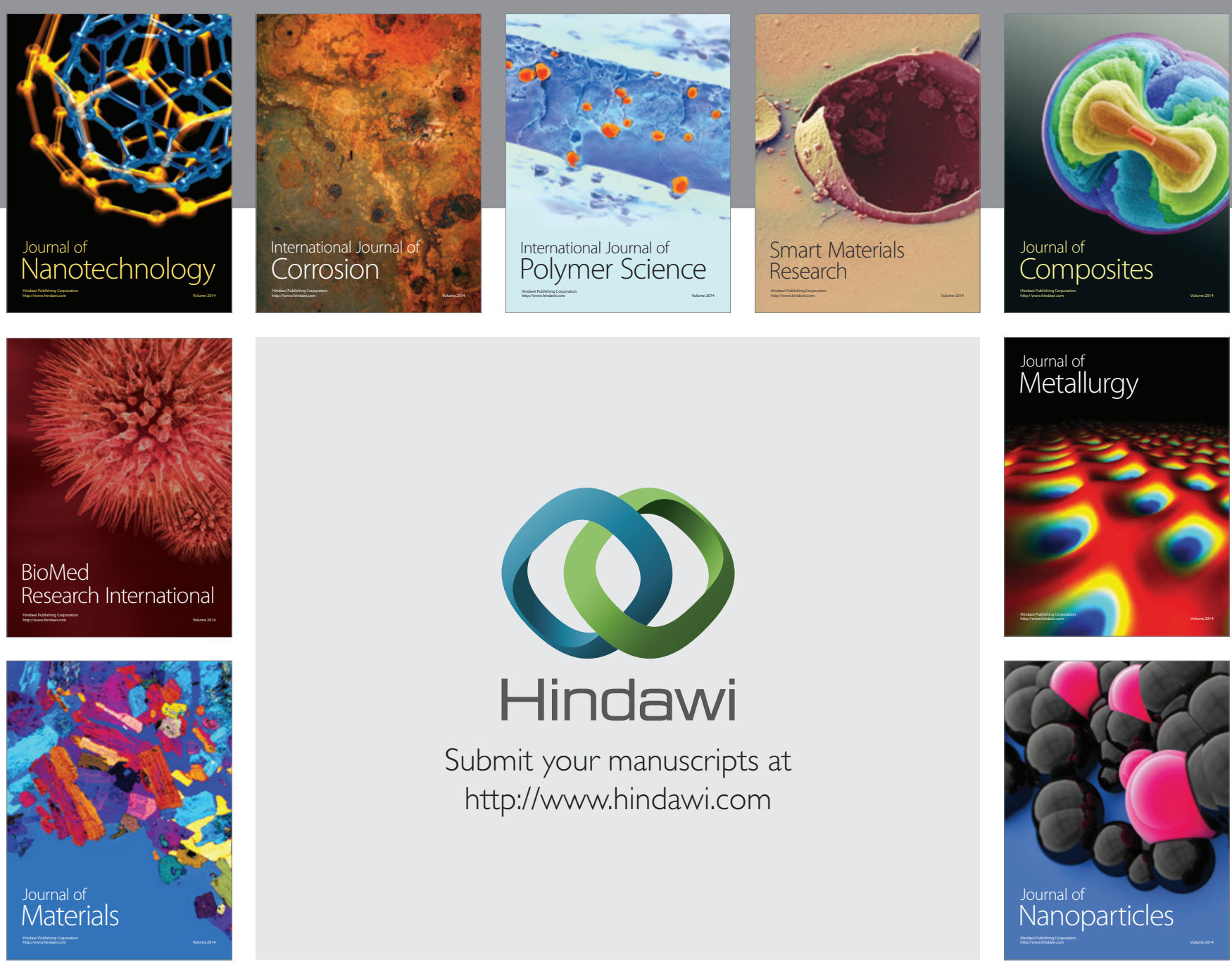

Submit your manuscripts at http://www.hindawi.com
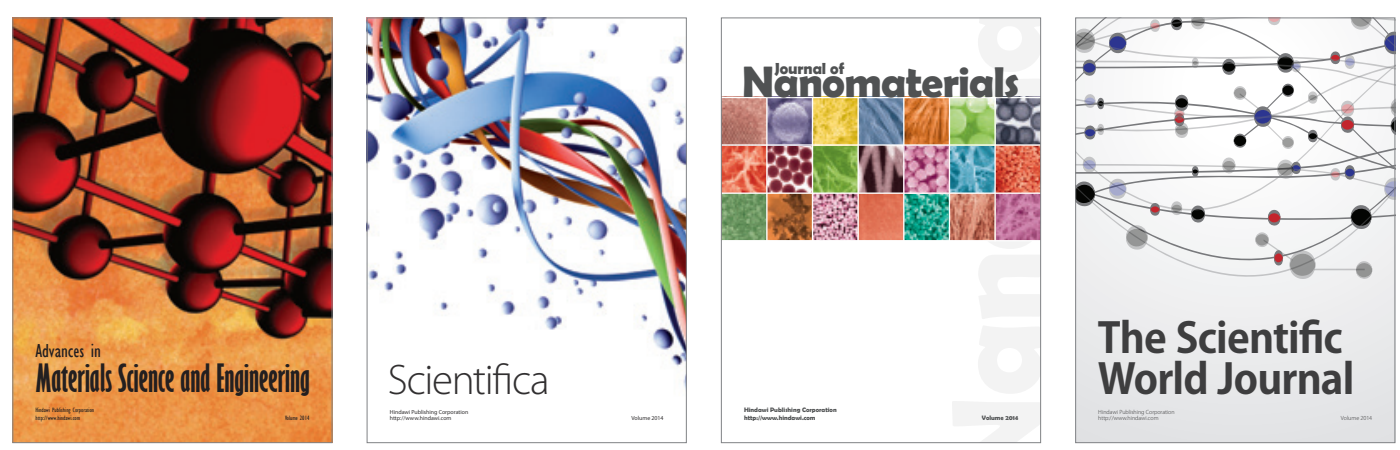

\section{The Scientific World Journal}
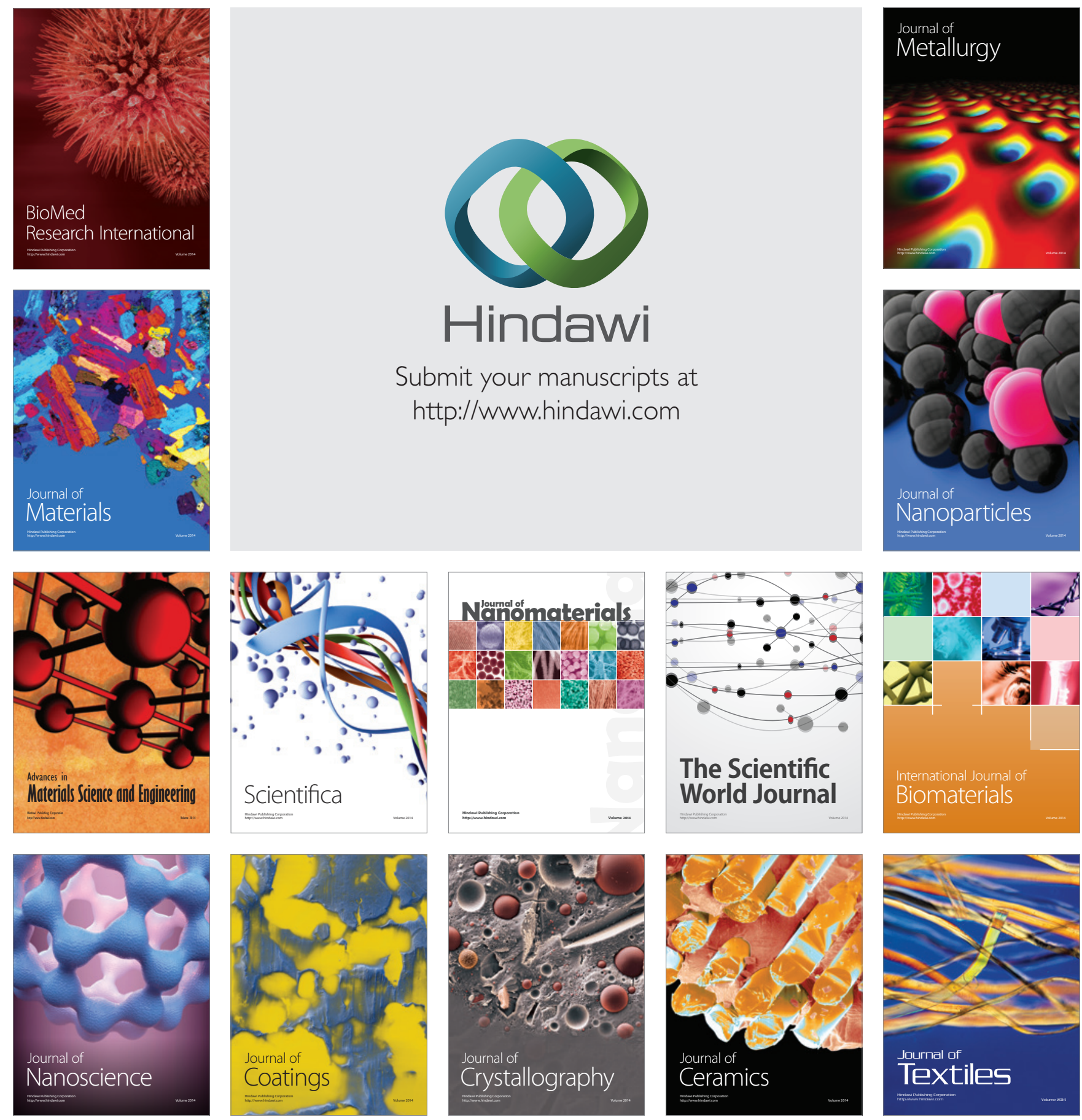